This article was published in Chemical Engineering Journal, 245, 191200, 2014

http://dx.doi.org/10.1016/j.cej.2014.02.024

\title{
Microencapsulation of essential oils with biodegradable polymeric carriers for cosmetic applications
}

Isabel M. Martins ${ }^{a, \Uparrow}$, Maria F. Barreiro ${ }^{b}$, Manuel Coelho ${ }^{c}$, Alírio E. Rodrigues ${ }^{a}$

a LSRE - Laboratory of Separation and Reaction Engineering, Associate Laboratory LSRE/LCM, Department of Chemical Engineering, Faculty of Engineering of University of Porto,

Rua Dr Roberto Frias, 4200-465 Porto, Portugal

b LSRE - Laboratory of Separation and Reaction Engineering, Associate Laboratory LSRE/LCM, Polytechnic Institute of Bragança, Campus Santa Apolónia Ap 1134, 5301-857 Bragança, Portugal

C LEPAE - Laboratory for Process, Environmental and Energy Engineering, Department of Chemical Engineering, Faculty of Engineering of University of Porto, Rua Dr Roberto Frias, 4200-465 Porto, Portugal

\footnotetext{
Abstract

Microencapsulation provides an important tool for cosmetic and/or pharmaceutical industry, enabling protection and controlled release of several active agents. The encapsulation of essential oils in core-shell or matrix particles has been investigated for various reasons, e.g., protection from oxidative decomposition and evaporation, odor masking or merely to act as support to ensure controlled release. A large number of microencapsulation methods have been developed in order to be adapted to different types of active agents and shell materials, generating particles with a variable range of sizes, shell thicknesses and permeability, providing a tool to modulate the release rate of the active principle.

With this work, an overview regarding properties and applications of essential oils and biodegradable polymers in the cosmetic field, focusing the use of polylactide as the base material to encapsulate thyme oil, as well as of microencapsulation processes with a particular emphasis on the coacervation, will be presented.
} 


\section{Introduction}

Nowadays, scientific advance is being used in the development of innovative products. Food, cosmetics, personal care and beauty/ pharmaceutical industries have become a multi-billion dollar international market [1-3]. In particular, the growth value of the beauty and personal care industry has been significant in emerging markets, such as Brazil, China, India, Indonesia and Argentina [4]. To have success in such competitive and demanding sector, the products must differentiate which can be achieved by means of using emergent technologies, such as microencapsulation.

Microencapsulation can promote cosmetic base products by introducing innovation, added functional properties and thus added value [5]. In this context it is important to develop novel processes, or optimize existing ones, to microencapsulate active principles with interest for cosmetic industry, thus contributing for innovative and high added value products creation, in response to human needs and desires.

Microcapsules are small particles with a size between 1 and $1000 \mu \mathrm{m}$ comprising an active agent surrounded by a natural or synthetic polymeric membrane. Microcapsules are composed by two parts, namely the core and the shell. The core (the internal part) contains the active agent (e.g., an essential oil), while the shell (the external part) protects the core from the outer environment [6]. Encapsulation can be achieved by a wide range of methods or techniques, providing isolation, entrapment, protection or controlled release of sensitive or reactive materials (e.g. flavors and fragrances) from/across the surrounding matter.

There are numerous industrial applications of microencapsulation. Some examples are carbonless paper, "scratch and sniff" fragrance sampling, "intelligent" textiles, controlled release of drugs, pesticides and cosmetic active agents. In conclusion, there are numerous possibilities to use microencapsulation as a technique to obtain products with high added value. Fig. 1 illustrates the distribution, in percentage, of microencapsulation over different fields of application. It is clear that the sector which has the highest level of applications is the drug sector (68\%), followed by the food (13\%) and cosmetic ( $8 \%$ ) ones. On the contrary, the electronics sector ac- counts only with $1 \%$ (the smallest percentage).

Microencapsulation can be used to protect fragrances or other active agents from oxidation caused by heat, light, moisture, from contact with other substances over a long shelf life, to prevent evaporation of volatile compounds and to control the release rate $[6,8,9]$.

The encapsulated agent can be released by several mechanisms, for example, mechanical action, heat, diffusion, $\mathrm{pH}$, biodegradation and dissolution. The selection of the technique and shell material depends on the final application of 
the product, considering physical and chemical stability, concentration, required particle size, re- lease mechanism and manufacturing costs.

In recent years the demand for fragranced products is growing and it is expected to expand and increase in diversity. Fragrances and flavors are important additives for products such as household detergents, laundry products or cosmetics [10].

Recent published patents in the area of microencapsulation suggest that both industrial and academic sectors are urging to explore this area, including in the fields of cosmetics and personal care products (Fig. 2). The cosmetic or personal care business is worth pursuing in view of the wide-ranging potential they hold. In recent years, encapsulation of cosmetic and personal care products ingredients has become very popular, attractive and the associated production processes technologically feasible. This is a consequence of the added value associated with the generated products, but also because compounds' functionality can be effectively preserved [11]. In conclusion, cosmetic technology is growing constantly in terms of raw materials, excipients and formulations of active agents [12]. It is thus desirable to keep in mind that consumers are more demanding and that microencapsulation remains a challenging art being important to increase the operative window in terms of processes and encapsulation materials (core and shell materials).

\section{Efficient microencapsulation methodologies}

\subsection{Microencapsulation methods}

Several methods have been purposed for microcapsule's production [13-22], in order to be adapted to different types of core and shell materials, as well as, to generate particles with various sizes, shell thickness and permeability, thus adjusting the release rate of the active principle. Generally these techniques can be divided into two major categories, namely chemical and physical methods; the latter one can be subdivided into physicochemical and physicomechanical techniques [6].

Spray drying is the most frequently used technique to encapsulate flavors (Fig. 3). It is a physicomechanical method developed in the 1930s being an attractive and versatile process [23]. Spray dry- ing can be described as a simple process, similar to a one stage dry- ing operation, capable of producing a wide range of microcapsules at good yield, including microcapsules loaded with fragrance or flavor oils [24]. Moreover, the process is adaptable to a wide range of feedstock and product specifications, i.e. it can be used with solutions, suspensions, slurries, melts and pastes [25]

By means of spray drying, active principles with quite distinct solubility 
properties can be encapsulated using various shell materials, being the partitioning of active principle between two immiscible phases avoided [26]. Nevertheless, spray drying has also some disadvantages; the equipment is very bulky and expensive [25]. Moreover, it produces a fine microcapsules powder which needs further processing such as agglomeration, and the overall thermal efficiency is low (uses large volumes of heated air passing through the chamber without contacting particles, thus not contributing directly for the drying). On the other hand, the use of spray drying technique for microencapsulation is limited by the available number of shell materials with good water solubility [27,28]. Still, the sol-gel encapsulation technology is a promising alternative to encapsulation aromas and flavors with organic polymers [29]. This encapsulation technology was introduced in the last decade and allows an effective control of biomolecules, drugs or essential oils released [30,31]. Taking into account the limitations of some processes and the physicochemical characteristics of essential oils, coacervation could be an attractive technique to encapsulate this type of active agents.

Coacervation techniques can be divided in two main groups: aqueous and organic. The coacervation in aqueous phase can only be used to encapsulate water insoluble materials (hydrophobic core materials presented in solid or liquid state). On the other hand, the coacervation in organic phase allows the encapsulation of hydrosoluble material, but requires the use of organic solvents [32].

Coacervation in aqueous phase can be classified into simple and complex, according to the involved phase separation mechanism. In simple coacervation, the polymer is salted out by the action of electrolytes, such as sodium sulfate, or desolvated by the addition of a water miscible non-solvent, such as ethanol, or by increasing/ decreasing temperature. These conditions promote the macromolecule-macromolecule interactions in detriment of the macromole- culesolvent interactions. On the other hand, complex coacervation is essentially driven by the attractive forces of oppositely charged polymers [33]. The coexistence of a coacervate phase made of concentrated polyelectrolytes and a diluted equilibrium phase depends on $\mathrm{pH}$, ionic strength and polyion concentrations [34].

The general outline of the coacervation process consists in three steps that occur under continuous stirring (see Fig. 4). The first step consists in the formation of an oil-in-water (o/w) emulsion (dispersion of the oil in a aqueous solution containing a surface-active hydrocolloid), the second comprises the formation of the coating (deposition the polymer coating upon the core material), and the last one is the stabilization of the coating (coating hardening, using thermal, crosslinking or desolvation techniques, to form self-sustaining microcapsules) [35,36]. The coacervate shell formation is driven by the surface tension difference between the coacervate phase, the water and the hydrophobic material. 
Coacervation offers numerous possibilities for the encapsulation of various types of active agents (solid or liquid core materials) [8,38-43]. It can be useful in many industrial sectors such as, food, cosmetic or pharmaceutical. Fig. 5 shows the number of publications as a function of the application market considering as key words coacervation plus the intended application. Additionally Table 1 shows a summary of patents dealing with coacervation putting in evidence the scope of the invention. Analyzing the results, food, cosmetic/fragrances/flavors and pharmaceuticals are the areas with the highest number of publications using coacervation as the technique to encapsulate active agents and, microencapsulation of fragrances by coacervation is an efficient way of adding oilbased fragrances to products.

\subsection{Encapsulation efficiency}

Encapsulation efficiency (content of core material effectively encapsulated) depends on several variables. The retention of the active agent inside the membrane shell is ruled by factors related to the chemical nature of the core, including its molecular weight, chemical functionality, polarity and volatility, shell material properties and the chosen microencapsulation technique. On the other hand, the hydrophobic properties of the surfactants also affect encapsulation efficiency. As an example, Fig. 6 shows the effect of using different surfactant systems during the emulsification stage, on thyme oil microencapsulation efficiency using a PLA- based shell material. It can be observed that when surfactants with

HLB (hydrophilic-lipophilic balance) values higher than 15.0 (Tween ${ }^{\circledR} 20$ (16.5) and Tween ${ }^{\circledR} 80$ (15.5)) were used, the amount of encapsulated thyme oil was low (around 30-40\%). On the other hand, a significant increase of encapsulated oil was found when Tergitol ${ }^{\mathrm{TM}} 15-\mathrm{S}-9$, a surfactant with HLB value of 13.3 , was used (around $65 \%$ ). The larger is the hydrophobic chain of surfactant the lower is the surface tension at the $\mathrm{o} / \mathrm{w}$ interface, becoming easier to form the emulsion. Nevertheless, thyme oil presents both polar and apolar compounds. From Fig. 6 we can also notice that the apolar compounds of thyme oil were preferentially encapsulated in detriment of the polar ones no matter the studied surfactant. With Tergitol ${ }^{\mathrm{TM}} 15-\mathrm{S}$ 9 , an encapsulation of $80 \%$ was achieved for the apolar compounds, while for the polar ones only 54\% was achieved. Since apolar compounds of thyme oil are preferentially encapsulated it means that the polar ones are not effectively protected within the capsule, thus remaining in the surrounding phase. This result shows that total encapsulation efficiency of thyme oil de- pends on polar and apolar components individual contribution [56]. 


\subsection{Encapsulation materials}

The most commonly used shell materials in coacervation are polysaccharides and sugars (gums, starches, celluloses, ciclodextrines); proteins (gelatine, casein, soy proteins); lipids (waxes, paraffin, oils); and synthetic polymers (acrylic polymers, poly(vinylpyrrolidone)). In a less extent, inorganic materials such as silicates, clays and polyphosphates can also be used. Table 2 shows a survey of illustrative examples of shell materials used in coacervation microencapsulation processes.

Despite of several systems proposed, biodegradable polymers have emerged as potential candidates for the development of carriers for targeting compounds to specific sites in the body.

During the last years, numerous processes for drug encapsulation have been developed using aliphatic polyesters, such us poly(lactic acid) (PLA) and copolymers of lactic and glycolic acids (e.g. PLGA) that are well known biodegradable polymers. The bio- degradability of these polymers can be tuned by incorporating in their main chain a variety of chemical groups such as ethers, anhydrides, carbonates, amides, ureas and urethanes [68-71].

Biodegradable polymers, such as PLA and PLGA (poly(lactide- co-glycolide)), have proven, since a long time, their capacity for applications in the field of controlled delivery systems [72,73]. The degradation behavior of biodegradable polymers is a very important property in the medical field especially in tissue engineering, and drug delivery. Their properties (such as degradation rate) are strongly defined by structural characteristics like the composition of the copolymer, molecular weight and nature of the chain end groups. Polylactide-coglycolide copolymers can be copolymerized to achieve various molecular architectures with a significant range of mechanical properties and degradation rates. Due to the methyl group presence, PLA is more hydrophobic than PLGA. Thus, PLA-based products degrade by hydrolysis much slower than PLGA-based counterparts.

PLA microcapsules have received intensive attention as delivery systems for drug encapsulation since they do not cause adverse tis- sue reaction [74]. This type of biodegradable polymeric carriers can be hydrolyzed in the body to form products that are easily reabsorbed or eliminated [74-75]. The adjustable physicochemical proprieties of PLA, such as swelling and biodegradation kinetics, or molecular interaction with potential embedded drugs, offer various possibilities towards the design of controlled release systems [76-79]. These properties of biodegradable polymers are strongly defined by structural features such as copolymer composition, molecular weight and nature of the chain end-groups. For example, the non-esterified carboxyl end groups increase the hydrophilicity of polymer promoting a faster and higher polymer swelling; consequently, a faster biodegradation in aqueous environment [76]. 


\section{Microencapsulation of essential oils}

The use of oils in the perfumery, cosmetics, and agriculture or food industries is quite common due to their aromatic properties. In addition, some essential oils have biological activities that can be used in the preparation of pharmaceutical products and functional foods [80]. Properties of essential oils can change depending on their origin and composition. Some oils have medicinal properties such as antioxidant activity, acting in fighting free radicals, anti-inflammatory activity and antimicrobial activity. Table 3 lists a set of essential oils that were subjected to microencapsulation.

Coacervation is widely used to encapsulate essential oils and typical examples of the used oils are given in Table 4.

\section{Microencapsulation and controlled release}

\subsection{Microcapsules morphology and release mechanisms}

Encapsulation systems can be classified according to four main morphologies: reservoir, double shell, matrix and polynucleated structures (Fig. 7). The main purpose of encapsulation is to entrap a core material into a protective matrix/shell that will confer unique properties in terms of controlled release, solubility or moisture resistance of microcapsules.

The protection of essential oils, perfumes, deodorants, moisturizes and other active agents in polymer carriers with the purpose of controlled release over a certain period of time has been a question of considerable research in recent years [2,86,106-111]. Controlled release technologies are used to deliver compounds such as drugs, pesticides, fragrances or flavors at prescribed rates, together with improved efficacy, safety and convenience [112]. Fig. 8 shows the schematic representation of the essential oil release through the polymeric microcapsule shell.

Nowadays, core-shell microcapsules are highly used in con- trolled release systems, especially in drug delivery, where the polymeric shell works as a permeable element with a selectivity that can determine the release behavior of the core material [113]. Delivery systems for drugs and other active ingredients and size- reduction technologies, such as microencapsulation, are at the frontier of advances in modern biotechnology. Focusing the developments in trans-dermal delivery systems microencapsulation introduces a new way for replacing current high-risk intravenous applications and drastically reduce undesirable side effects of drugs and active ingredients [114].

The particular properties of the polymeric network, such as, chain length, flexibility and mobility, water-uptake and swelling behavior, plasticization extent, or potential 
interactions between polymer and active agent will affect the diffusion rate across the polymeric matrix, and therefore, the oil release [68].

According to Del Valle et al. [70] diffusion of active agents occurs when a drug or oils passes through the polymer that forms the controlled release device. Nevertheless, the release of the active agent from delivery systems can be classified based on other mechanisms, such as, erosion (the product gradually dissolves in membrane shell), diffusion (the oil diffuses out of delivery system), extraction (mechanical forces during chewing or processing enlarge area of oil) and burst (a reservoir system ruptures under influence of mechanical or osmotic forces) [115]. Several diffusion models have been proposed in the literature to describe the release of an active agent from microcapsules [86,116-123].

Table 5 presents a summary of the model release related to the diffusion of active agents through the polymeric membranes of microcapsules.

A mathematical release model is based on equations that de- scribe the real phenomena, such as mass transport by diffusion, dissolution of active agent, and for example, the transition of a polymer from the glassy to the rubbery state [126]. Fig. 9 shows different types of classification for drug delivery systems. In reservoir system if the active agent concentration at the inner mem- brane surface continuously decreases with time and if the active agent permeability through the barrier remains constant, a first or- der release kinetics is obtained.

If the initial active agent concentration exceeds the active agent solubility in reservoir device, it results a constant active agent con- centration (saturated solution) at the inner membrane surface, and still if the properties of the release rate controlling barrier (such as, thickness and permeability for the active agent) remain constant, a zero order release kinetic is obtained.

On the other hand, in the case of matrix devices, the system geometry extensively affects the resulting active agent release kinetics. In that case, for each system is necessary to develop a specific mathematical equation [126].

\subsection{Diffusion characteristics of poly(lactic acid) microcapsules}

Microcapsules morphology can be analyzed by microscopy. This technique is a powerful tool to study microcapsules structure and formation. For example, Fig. 10 shows optical and cryogenic scanning electron microscopy images of PLA microcapsules with thyme oil reported by Martins et al. [37,56,96]. Images obtained through optical microscopy demonstrate that droplets of thyme oil have been individually encapsulated as spherical particles with- out noticeable agglomeration. On the other hand the Cryogenic Scanning Electron Microscopy (Cryo-SEM) image confirmed the rough surface of PLA microcapsules with some visible pinholes, cracks and pores (see, Fig. 10(b)) [37]. Furthermore, the PLA mem- brane covering the thyme oil is clearly exposed as depicted by the Laser Scanning Confocal Microscopy 
(LSCM) image (Fig. 11). The thyme oil - core is not labeled (black) and the PLA polymer layer is labeled with Coumarin 6 (green). Through this figure it was possible to corroborate reservoir-type of PLA microcapsules produced according the method developed by Martins et al. where Coumarin 6 was added to the PLA solution [37]. The release rate of thyme oil, as described in the work of Mast- romatteo et al. [127] dealing with the study of active food packaging, is affected by film thickness and polymer concentration [127]. On the other hand, release tests performed by Passino et al. [119] have shown that the diffusion of Thymus oil through the gelatine microcapsules is affected not only by the characteristics of the polymeric membrane but also by the type of used oil. The differences found in the release behavior might be due to the different hydrophilic characteristics of the oil. In fact, the percentage of polar compounds of oil can favor the entrapment of aqueous phase into de microcapsules during the coacervation process and consequently slows down its diffusion [119]. Nevertheless, the release rate profiles of thymol from the PCL (poly(e-caprolactone)), PLA, and 50/50 hybrid nanofibrous samples, performed by Karami et al. [128] point out a bi-phasic release profiles. The Fickian diffusion was the dominant mechanism of thymol release from the polymeric matrices. The diffusion of thymol through the nanofibrous samples could be divided into two phases: thymol released before 12 $\mathrm{h}$ and then between 12 and $48 \mathrm{~h}$, where the burst and rapid release of thymol was related to the adsorption and rapid diffusion of it from the surface of the nanofibrous samples.

The release studies performed by Martins et al. [96,129] con- tribute to develop a diffusion model for thyme oil compounds across the PLA shell. The release tests allowing determining the corresponding diffusion coefficients and thus describing the re- lease behavior with time. The developed model can be applied to other single-layer microcapsule systems. In this work the calculated and experimental diffusion profiles of oil components across the polymeric membrane were compared. Fig. 12 shows the re- lease kinetics for thymol during the first hour and a 5 days period. It is observed through Fig. 12 that the diffusion coefficient is $1.39 \times 10^{-15} \mathrm{~m}^{2} / \mathrm{s}$ for thymol, the polar component, in first hour. Furthermore, for the apolar component, p-cymene, the diffusion coefficient for the first hour of release is lower than that obtained for thymol. This behavior is in accordance with the previously observed by Wischke and Schwendeman, where the release differences were attributed to the distinct hydrophobic characteristics of the two compounds $[68,96]$. 


\section{Conclusions}

In this work a literature survey regarding microencapsulation for cosmetic applications was presented, focusing the microencapsulation of essential oils by coacervation with biodegradable polymeric materials. Microencapsulation by coacervation of thyme oil with PLA is presented as an example.

Summarizing, microencapsulation efficiency depends on several variables, namely the chemical nature of the core, properties of the shell/matrix material, the hydrophobic character of the used surfactants, as well as of the chosen microencapsulation technique. In fact, the generated microcapsules in what concerns size, shape and stability, is affected by the used coacervation process conditions, being particularly relevant the chosen surfactant. In the case of the focused process (encapsulation of thyme oil with PLA) it was verified a higher encapsulation efficiency for apolar compounds of thyme oil. The best encapsulation results were achieved with Tergitol ${ }^{\mathrm{TM}} 15-\mathrm{S}-9$ (HLB of 13.3): 80\% for the apolar compounds and $54 \%$ for the apolar ones. In what concerns the release profile of thymol (major polar compound of thyme oil) from the PLA microcapsules it can be explained by a diffusion mechanism, in accordance with the developed model and was found to be in good agreement with the experimental measurements.

\section{Acknowledgments}

Financial support for this work was provided by LSRE financing by FEDER/POCI/2010, for which the authors are thankful and Isabel Martins acknowledges her Ph.D scholarship by Fundação para a Ciência e a Tecnologia (FCT) (SFRH/BD/43215/2008).

The authors gratefully acknowledge Dr. Paula Sampaio from the IBMC-INEB Associated Laboratory, for the assistance on Laser Scanning Confocal Microscopy (LSCM) analysis.

\section{Appendix A. Supplementary material}

Supplementary data associated with this article can be found, in the online version, at http://dx.doi.org/10.1016/j.cej.2014.02.024 


\section{References}

[1] L. Zev, Microencapsulation: an overview of the technology landscape, in: R. Rosen Meyer (Ed.) Delivery System Handbook for Personal Care and Cosmetic Products, William Andrew Publishing, Norwich, NY, 2005, pp. 181190.

[2] R. Costa, G.D. Moggridge, P.M. Saraiva, Chemical product engineering: an emerging paradigm within chemical engineering, AIChE J. 52 (2006) 19761986.

[3] J.A. Wesselingh, S. Kill, M.E. Vild, Design \& Development of Biological, Chemical, Food and Pharmaceutical Products, In: Wiley (Ed.), Chichester, UK, 2007.

[4] I. Euromonitor, Beauty and personal care 2011: corporate strategies in and beyond the BRICs, in: Euromonitor International (Ed.), 2012, 2011.

[5] H. Michael, Chemical product engineering-the third paradigm, Comput. Chem. Eng. 33 (2009) 947-953.

[6] S.K. Ghosh, Functional coatings and microencapsulation: a general perspective, in: Swapan Kumar Ghosh (Ed.) Functional Coatings, Wiley-VCH Verlag GmbH \& Co. KGaA, 2006, pp. 1-28.

[7] Isi, ISI web of knowledge, in, 2011.

[8] S.O. Lumsdon, T.E. Friedmann, J.H. Green. Encapsulation of oils by coacervation. WIPO Patent WO/2005/105290, 2005.

[9] J.J.G.V. Soest, Encapsulation of fragrances and flavours: a way to control odour and aroma in consumer products, in: R.G. Berger (Ed.) Flavours and Fragrances - Chemistry, Bioprocessing and Sustainability, Springer, Germany, 2007, p. 439.

[10] Gate2tech, Application of microcaencapsulation, in, 2008.

[11] I.M. Society, Encapsulation for Cosmetics and Personal, Care, in, 2006.

[12] S. Benita, M.-C. Martini, Cosmetic Applications of Vesicular Delivery Systems, in: Simon Benita (Ed.), Microencapsulation: Methods and Industrial Applications, Marcel Dekket Inc., New York, 1996.

[13] K. Hirech, S. Payan, G. Carnelle, L. Brujes, J. Legrand, Microencapsulation of an insecticide by interfacial polymerisation, Powder Technol. 130 (2003) 324330.

[14] P.L. Madan, Microencapsulation. 1. Phase separation or coacervation, Drug Dev. Ind. Pharm. 4 (1978) 95-116.

[15] J.H. Ahn, Y.P. Kim, Y.M. Lee, E.M. Seo, K.W. Lee, H.S. Kim, Optimization of microencapsulation of seed oil by response surface methodology, Food Chem. 107 (2008) 98-105.

[16] A.Z. Chen, Y. Li, F.T. Chau, T.Y. Lau, J.Y. Hu, Z. Zhao, D.K.W. Mok, Microencapsulation of puerarin nanoparticles by poly(L-lactide) in a 
supercritical CO2 process, Acta Biomater. 5 (2009) 2913-2919.

[17] K. Bauckhage, O. Andersen, S. Hansmann, W. Reich, P. Schreckenberg,

Production of fine powders by ultrasonic standing wave atomization, Powder Technol. 86 (1996) 77-86.

[18] D. Ascheri, M. Marquez, E. Martucci, Microencapsulação de óleo essencial de laranja: selecção de material de parede, Ciênc. Tecnol. Aliment 23 (2003) $1-6$.

[19] R. Bodmeier, H.G. Chen, Preparation of biodegradable poly(dl-lactide) microparticles using a spray-drying technique, J. Pharm. Pharmacol. 40 (1988) 754-757.

[20]W.S. Yin, M.Z. Yates, Encapsulation and sustained release from biodegradable microcapsules made by emulsification/freeze drying and spray/freeze drying,

J. Colloid Interface Sci. 336 (2009) 155-161.

[21] H. Anwar, J. Weissbrodt, B. Kunz, Microencapsulation of fish oil by spray granulation and fluid bed film coating, J. Food Sci. 75 (2010) E359-E371.

[22] L.H. Hung, S.Y. Teh, J. Jester, A.P. Lee, PLGA micro/nanosphere synthesis by droplet microfluidic solvent evaporation and extraction approaches, Lab Chip 10 (2010) 1820-1825.

[23] K.G.H. Desai, H.J. Park, Recent developments in microencapsulation of food ingredients, Drying Technol. 23 (2005) 1361-1394.

[24] C. Thies, Microencapsulation, in: Inc John Wiley \& Sons (Ed.) KirkOthmer Encyclopedia of Chemical Technology, 2000, pp. 438-463.

[25] N. Andrews, Advantages \& Disadvantages of Spray Drying, in, 2011.

[26] C.A. Finch, R. Bodmeier, Microencapsulation, in: Ullmann's Encyclopedia of Industrial Chemistry, Wiley-VCH Verlag GmbH \& Co. KGaA, 2000.

[27] M.D.L. Moretti, G. Sanna-Passino, S. Demontis, E. Bazzoni, Essential oil formulations useful as a new tool for insect pest control, AAPS PharmSciTech 3 (2002) E13.

[28] A. Gharsallaoui, G. Roudaut, O. Chambin, A. Voilley, R. Saurel, Applications of spray-drying in microencapsulation of food ingredients: an overview, Food Res. Int. 40 (2007) 1107-1121.

[29] M. Pagliaro, Silica-Based Materials for Advanced Chemical Applications, RSC Publishing, Cambridge, 2009.

[30]R. Ciriminna, M. Pagliaro, Sol-gel microencapsulation of odorants and flavors: opening the route to sustainable fragrances and aromas, Chem. Soc. Rev. 42 (2013) 9243-9250.

[31] H. Nguyen-Ngoc, C. Tran-Minh, Sol-gel process for vegetal cell encapsulation, Mater. Sci. Eng C - Biomimetic Supramol. Syst. 27 (2007) 607-611. 
[32] H.S.O.L. Kas, Microencapsulation using coacervation/phase-separation: an overview of the technique and applications, in: Marcel-Dekker (Ed.) Handbook of pharmaceutical controlled release technology, Wise, D.L., New York, 2000.

[33] B. Gander, M.J. Blanco-Príeto, C. Thomasin, C. Wandrey, D. Hunkeler, Coacervation and phase separation, in: Encyclopedia of Pharmaceutical Technology, 2006.

[34] V. Ducel, J. Richard, P. Saulnier, Y. Popineau, F. Boury, Evidence and characterization of complex coacervates containing plant proteins: application to the microencapsulation of oil droplets, Colloids Surf. A 232 (2004) 239-247. [35] J.J.G. Soest, Encapsulation of fragrances and flavours: a way to control odour and aroma in consumer products, in: R.G. Berger (Ed.), Flavours and Fragrances: Chemistry, Bioprocessing and Sustainability, Springer, Germany, 2007, p. 439.

[36] T.E. Friedmann, S.O. Lumsdon, J.H. Green, Encapsulation of oils by coacervation, United States Patent 20090189304, 2009.

[37] I.M. Martins, S.N. Rodrigues, F. Barreiro, A.E. Rodrigues, Microencapsulation of thyme oil by coacervation, J. Microencapsul. 26 (2009) $667-675$.

[38] J.-P. Benoit, J. Richard, C. Thies, Method for preparing microcapsules comprising active materials coated with a polymer and novel microcapsules in particular obtained according to the method, United States Patent. 6183783, 2001.

[39] M.R. Juliá Ferres, P. Erra Serrabasa, I. Muñoz Lirón, A. Ayats Llorens, Procedimiento para la preparación de cápsulas y encapsulación de sustancias. OFICINA ESPAÑOLA DE PATENTES Y MARCAS, 1999.

[40] S. Magdassi, Y. Vinetsky, Microencapsulation of Oil-in-Water Emulsions by Proteins, in: S. Benita (Ed.), Microencapsulation: Methods and Industrial Applications, Marcel-Dekker, New York, 1996, pp. 21-34.

[41] A.M. Schobel, Encapsulated active agents, for instance encapsulated fragrances and flavours, and process therefor, European Patent Application, EP0170752, 1986.

[42] J.C. Soper. Method of encapsulation food or flavor particles using warm water fish gelatin, and capsules produced therefrom, WIPO Patent Application, WO/ 1996/020612, 1996.

[43] D.M. Whitaker Sr, Stabilized perfume-containing microcapsules and method of preparing the same, United States Patent. 5051305, 1991.

[44] H. Georg, Encapsulation process by complex coacervation using inorganic polymers, United States Patent US3639256, 1972.

[45] R.W. Baker, Y. Ninomiya, Microcapsules prepared by coacervation, United States Patent 4808408, 1989. 
[46] A. Tanner, Kathleen, Dubois, Zerlina, Guzdar, Cosmetic cleasing composition with dual blooming perfume system, Wipo Patent Application WO/1995/ 016432, 1995.

[47] K.W. Leong, R.V. Azhari, Controlled release of pharmaceutically active substances from coacervate microcapsules, United States Patent $5759582,1998$.

[48] J.T. Baravetto, E.M. Schrader, T.W. Coffindaffer, S.M. Guskey, Conditioning shampoo composition, United States Patent 5980877, 1999.

[49] R.J. Carswell, A.N. Jarvis, A.L. Killey, W. Mooney, A.P. Parker, E.J. Peckham, Z. Shen, Fabric care composition, United States Patent 6255271, 2001.

[50] J.C. Soper, T.M. Thomas, Enzymatically protein-encapsulating oil particles by complex coacervation, United States Patent 6325951, 2001.

[51] J.R. Lawson, M. Vandebroek, J.D. Vuijk, Packaged product, United States Patent 6595437, 2003.

[52] J.-P. Benoit, J. Richard, E. Fournier, S. Liu, Method for encapsulating active substances by coacervation of polymers in non-chlorinated organic solvent, European Patent EP1216091, 2004.

[53] G. Dardelle, V. Normand, Method for preparing microcapsules by coacervation, United States Patent 20090253165, 2009.

[54] J.-T. Simmonet, B. Biatry, F. Prigent, Core/skin type capsules and preparation method, EP2011565, 2009.

[55] T. Sengupta, D.A. Fernandez, D.S. Kellogg, M.K. Mishra, W.R. Sweeney, Solid flavor encapsulation by applying complex coacervation and gelation technology, Wipo Patent Application WO/2011/117738, 2011.

[56] I.M. Martins, S.N. Rodrigues, M.F. Barreiro, A.R.E. Rodrigues, Polylactide-based thyme oil microcapsules production: evaluation of surfactants, Ind. Eng. Chem. Res. 50 (2010) 898-904.

[57] B. Boh, B. Sumiga, Chemical methods of microencapsulation of fragrances, in: Bioencapsulation Industrial Symposium (Ed.), Geneva, 2010.

[58] J. Lazko, Y. Popineau, J. Legrand, Soy glycinin microcapsules by simple coacervation method, Colloids Surf. B 37 (2004) 1-8.

[59] O. Siddiqui, H. Taylor, Physical factors affecting microencapsulation by simple coacervation of gelatin, J. Pharm. Pharmacol. 35 (1983) 70-73.

[60] A.J.P. Santinho, N.L. Pereira, O. De Freitas, J.H. Collett, Influence of formulation on the physicochemical properties of casein microparticles, Int. J. Pharm. 186 (1999) 191-198.

[61] V.L. Gonçalves, M.C.M. Laranjeira, V.T. Fávere, R.C. Pedrosa, Effect of crosslinking agents on chitosan microspheres in controlled release of diclofenac sodium, Polímeros 15 (2005) 6-12.

[62] A.R. Bachtsi, C. Kiparissides, Synthesis and release studies of oil- 
containing poly(vinyl alcohol) microcapsules prepared by coacervation, J. Controlled Release 38 (1996) 49-58.

[63] A.S. Prata, M.H.A. Zanin, M.I. Ré, C.R.F. Grosso, Release properties of chemical and enzymatic crosslinked gelatin-gum Arabic microparticles containing a fluorescent probe plus vetiver essential oil, Colloids Surf. B 67 (2008) 171-178.

[64] R.T. Thimma, S. Tammishetti, Study of complex coacervation of gelatin with sodium carboxymethyl guar gum: microencapsulation of clove oil and sulphamethoxazole, J. Microencapsul. 20 (2003) 203-210.

[65] M. Sefton, W.K. Stevenson, Microencapsulation of Live Animal Cells Using Polyacrylates, in: Robert S. Langer, Nicholas A. Peppas (Eds.), Biopolymers I, Springer, Berlin Heidelberg, 1993, pp. 143-197.

[66] F. Mark, H. Georg, Encapsulation process by complex coacervation using inorganic polyphosphates and organic hydrophilic polymeric material, United States Patent 3697437, 1972.

[67] H. Georg, Encapsulation process by complex coacervation using polymers and capsule product therefrom, United States Patent 3692690, 1972.

[68] C. Wischke, S.P. Schwendeman, Principles of encapsulating hydrophobic drugs in PLA/PLGA microparticles, Int. J. Pharm. 364 (2008) 298-327.

[69] T. Chandy, G.S. Das, R.F. Wilson, G.H.R. Rao, Development of polylactide microspheres for protein encapsulation and delivery, J. Appl. Polym. Sci. 86 (2002) 1285-1295.

[70] E.M.M. Del Valle, M.A. Galán, R.G. Carbonell, Drug delivery technologies: the way forward in the new decade, Ind. Eng. Chem. Res. 48 (2009) 2475-2486.

[71] E. Pálinkó-Biró, G. Rónaszèki, H.P. Merkle, B. Gander, Release kinetics and immunogenicity of parvovirus microencapsulated in PLA/PLGA microspheres, Int. J. Pharm. 221 (2001) 153-157.

[72] T. Heya, Y. Mikura, A. Nagai, Y. Miura, T. Futo, Y. Tomida, H. Shimizu, H. Toguchi, Controlled release of thyrotropin releasing hormone from microspheres: evaluation of release profiles and pharmacokinetics after subcutaneous administration, J. Pharm. Sci. 83 (1994) 798-801.

[73] I. Lancranjan, C. Bruns, P. Grass, P. Jaquet, J. Jervell, P. Kendall-Taylor, S.W.J.

Lamberts, P. Marbach, H. Ørskov, G. Pagani, M. Sheppard, L. Simionescu, Sandostatin LAR $^{\circledR}$ : pharmacokinetics, pharmacodynamics, efficacy, and tolerability in acromegalic patients, Metabolism 44 (1995) 18-26.

[74] Y.-Y. Huang, T.-W. Chung, T.-W. Tzeng, Drug release from PLA/PEG microparticulates, Int. J. Pharm. 156 (1997) 9-15.

[75] K. Hong, S. Park, Preparation of poly(-lactide) microcapsules for fragrant 
fiber and their characteristics, Polymer 41 (2000) 4567-4572.

[76] M.J. Blanco-Príeto, M.A. Campanero, K. Besseghir, F. Heimgatner, B. Gander, Importance of single or blended polymer types for controlled in vitro release and plasma levels of a somatostatin analogue entrapped in PLA/PLGA microspheres, J. Controlled Release 96 (2004) 437-448.

[77] B. Gander, H.P. Merkle, V.P. Nguyen, N.-T. Ho, A new thermodynamic model to predict protein encapsulation efficiency in poly(lactide) microspheres, J. Phys. Chem. 99 (1995) 16144-16148.

[78] M.A. Tracy, K.L. Ward, L. Firouzabadian, Y. Wang, N. Dong, R. Qian, Y. Zhang, Factors affecting the degradation rate of poly(lactide-co-glycolide) microspheres in vivo and in vitro, Biomaterials 20 (1999) 1057-1062.

[79] Y.J. Wang, Development of new polycations for cell encapsulation with alginate, Mater. Sci. Eng. C - Biomimetic Supramol. Syst. 13 (2000) 59-63. [80] M.G.D.V. Silva, F.J.D.A. Matos, P. Roberto, O. Lopes, F.O. Silva, M.T. Holanda, Composition of essential oils from three Ocimum species obtained by steam and microwave distillation and supercritical CO2 extraction, ARKIVOC, vi (2004) 66-71.

[81] S.-J. Park, Y.-S. Shin, J.-R. Lee, Preparation and characterization of microcapsules containing lemon oil, J. Colloid Interface Sci. 241 (2001) 502-508. [82] F. Weinbreck, M. Minor, C.G. De Kruif, Microencapsulation of oils using whey protein/gum arabic coacervates, J. Microencapsul. 21 (2004) 667-679. [83] A. Sipailiene, P.R. Venskutonis, R. Baranauskiene, Antimicrobial activity of commercial samples of thyme and marjoram oils, J. Essent. Oil Res. 18 (2006) 698. [84] B. Solomon, F.F. Sahle, T. Gebre-Mariam, K. Asres, R.H.H. Neubert, Microencapsulation of citronella oil for mosquito-repellent application: formulation and in vitro permeation studies, Eur. J. Pharm. Biopharm. (2011).

[85] W.-C. Hsieh, C.-P. Chang, Y.-L. Gao, Controlled release properties of chitosan encapsulated volatile citronella oil microcapsules by thermal treatments, Colloids Surf. B 53 (2006) 209-214.

[86] T. Gumi, S. Gascon, C. Torras, R. Garcia-Valls, Vanillin release from macrocapsules, Desalination 245 (2009) 769-775.

[87] M.A. Mortenson, G.A. Reineccius, Encapsulation and release of menthol. Part 1: the influence of OSAn modification of carriers on the encapsulation of L- menthol by spray drying, Flavour Frag. J. 23 (2008) 392-397.

[88] C. Arneodo, J.P. Benoit, C. Thies, Preliminary study of microencapsulation of essential oils by complex coacervation, STP Pharma Sci. 2 (1986) 303-306. [89] G. Costa, Insect repellent fabric, United States Patent 7887826, 2011. [90] J.R. Kim, S. Sharma, Acaricidal activities of clove bud oil and red thyme oil using microencapsulation against HDMs, J. Microencapsul. 28 (2011) 82-91. [91] Z. Dong, Y. Ma, K. Hayat, C. Jia, S. Xia, X. Zhang, Morphology and release profile of microcapsules encapsulating peppermint oil by complex coacervation, 
J. Food Eng. 104 (2011) 455-460.

[92]J. Adamiec, Moisture sorption characteristics of peppermint oil microencapsulated by spray drying, Drying Technol. 27 (2009) 1363-1369. [93] A. Blake, P. Cadby, F. Näf, Flavor (Flavour) compounds: production methods, in: Caballero Editor-in-Chief: Benjamin (Ed.) Encyclopedia of Food Sciences and Nutrition (Second Edition), Academic Press, Oxford, 2003, pp. $2517-2524$.

[94] X. Jun-Xia, Y. Hai-Yan, Y. Jian, Microencapsulation of sweet orange oil by complex coacervation with soybean protein isolate/gum Arabic, Food Chem. 125 (2011) 1267-1272.

[95] J. Janda, D. Bernacchi, S. Frieders, Microencapsulation process, 1995.

[96] I.M. Martins, S.N. Rodrigues, M.F. Barreiro, A.E. Rodrigues, Release of thyme oil from polylactide microcapsules, Ind. Eng. Chem. Res. 50 (2011) 1375213761.

[97] D. Fredj, F. Dietlin, New method of encapsulation of volatile substances and phyto-aromatic compositions thereby obtained, Institut National de la Propriété Industrielle, 1984.

[98] A. Ribeiro, P. Arnaud, S. Frazao, F. Venâncio, J.C. Chaumeil, Development of vegetable extracts by microencapsulation, J. Microencapsul. 14 (1997) 735- 742. [99] K. Golz-Berner, L. Zastrow, Perfume compositions with a scent sequence, 2003.

[100] Y. Maekawa, S. Miyano, K. Yazawa, A. Kondo, Aqueous printing ink containing perfume-containing microcapsules, 1975.

[101] C. Arneodo, A. Baszkin, J.P. Benoit, C. Thies, Interfacial tension behavior of citrus oils against phases formed by complex coacervation of gelatin, in: Flavor Encapsulation, American Chemical Society, 1988, pp. 132-147.

[102] B. Scher Herbert, Microencapsulated pesticides, in: Controlled Release Pesticides, AMERICAN CHEMICAL, SOCIETY, 1977, pp. 126-144.

[103] Y.G. Xing, X.H. Li, Q.L. Xu, C.X. Shao, J. Yun, CEAM 2011: Antimicrobial activity of microencapsulated cinnamon oil and its application on cherry tomato, in: 2011 International Conference on Chemical Engineering and Advanced Materials, Changsha, 2011, pp. 2307-2310.

[104] J.C. Soper, Method of encapsulating food or flavor particles using warm water fish gelatin, and capsules produced therefrom, 1997.

[105] C. Silva, A. Ribeiro, D. Ferreira, F. Veiga, Administração oral de peptídeos e proteínas: II. Aplicação de métodos de microencapsulação, Revista Brasileira de Ciências Farmacêuticas 39 (2003) 1-20.

[106] N.A. Peppas, D.J. Am Ende, Controlled release of perfumes from polymers. II. Incorporation and release of essential oils from glassy polymers, J. Appl. Polym. Sci. 66 (1997) 509-513.

[107] R.R. Calkin, J.S. Jellinek, Perfumery: practice and principles, in: Willey 
(Ed.), New York, 1994.

[108] N.A. Peppas, L. Brannon-Peppas, Controlled release of fragrances from polymers I. Thermodynamic analysis, J. Control. Release 40 (1996) 245-250. [109] C. Thies, A Survey of Microencapsulation Processes, in: Simon Benita (Ed.), Microencapsulation: Methods and Industrial Applications, Marcel Dekker, New York, 1996, p. 20.

[110] B. Peña, M. Casals, C. Torras, T. Gumí, R. Garcia-Valls, Vanillin release from polysulfone macrocapsules, Ind. Eng. Chem. Res. 48 (2009) 1562-1565. [111] R. Costa, P. Elliott, P.M. Saraiva, D. Aldridge, G.D. Moggridge, Development of sustainable solutions for zebra mussel control through chemical product engineering, Chin. J. Chem. Eng. 16 (2008) 435-440.

[112] M.S. Romero-Cano, B. Vincent, Controlled release of 4-nitroanisole from poly(lactic acid) nanoparticles, J. Controlled Release 82 (2002) 127-135.

[113] H.L. Guo, X.P. Zhao, J.P. Wang, The relation between narrow-dispersed microcapsules and surfactants, J. Microencapsul. 22 (2005) 853-862.

[114] E. Yechiel, R.L. Coste, From Ancient Potions to Modern Lotions: A Technology Overview and Introduction to Topical Delivery Systems, Elsom Research Co., Inc., San Antonio, TX, 2004.

[115] J. Ubbink, A. Schoonman, Flavor delivery systems, Kirk-Othmer Encycl. Chem. Technol. 11 (2001) 527-563.

[116] M. Marucci, G. Ragnarsson, U. Nyman, A. Axelsson, Mechanistic model for drug release during the lag phase from pellets coated with a semi-permeable membrane, J. Controlled Release 127 (2008) 31-40.

[117] W.Y. Kwok, C. Kiparissides, P. Yuet, T.J. Harris, M.F.A. Goosen, Mathematical modelling of protein diffusion in microcapsules. A comparison with experimental results, Can. J. Chem. Eng. 69 (1991) 361-370.

[118] Y. Lü, M. Bülow, Analysis of diffusion in hollow geometries, Adsorption 6 (2000) 125-136.

[119] G. Sanna Passino, E. Bazzoni, M.D.L. Moretti, Microencapsulated essential oils active against indianmeal moth, Boletín de Sanidad Vegetal. Plagas, 30 (1.1) (2004) 125-132.

[120] S. Muschert, F. Siepmann, B. Leclercq, B. Carlin, J. Siepmann, Prediction of drug release from ethylcellulose coated pellets, J. Controlled Release 135 (2009) 71-79.

[121] E.M. Tavera, S.B. Kadali, H.G. Bagaria, A.W. Liu, M.S. Wong, Experimental and modeling analysis of diffusive release from single-shell microcapsules, AIChE J. 55 (2009) 2950-2965.

[122] S.A. Cryer, S.L. Wilson, Modeling approach to assess clustering impact on release rates of pesticides from microencapsulated products, J. Agr. Food Chem. 57 (2009) 5443-5451.

[123] P. Borgquist, P. Nevsten, B. Nilsson, L.R. Wallenberg, A. Axelsson, 
Simulation of the release from a multiparticulate system validated by single pellet and dose release experiments, J. Controlled Release 97 (2004) 453-465. [124] H.N. Yow, X. Wu, A.F. Routh, R.H. Guy, Dye diffusion from microcapsules with different shell thickness into mammalian skin, Eur. J. Pharm. Biopharm. 72 (2009) 62-68.

[125] E. Mascheroni, V. Guillard, F. Nalin, L. Mora, L. Piergiovanni, Diffusivity of propolis compounds in Polylactic acid polymer for the development of anti- microbial packaging films, J. Food Eng. 98 (2010) 294-301.

[126] J. Siepmann, F. Siepmann, Mathematical modeling of drug delivery, Int. J. Pharm. 364 (2008) 328-343.

[127] M. Mastromatteo, G. Barbuzzi, A. Conte, M.A. Del Nobile, Controlled release of thymol from zein based film, Innovative Food Sci. Emerg. Technol. 10 (2009) 222-227.

[128] Z. Karami, I. Rezaeian, P. Zahedi, M. Abdollahi, Preparation and performance evaluations of electrospun poly(e-caprolactone), poly(lactic acid), and their

hybrid (50/50) nanofibrous mats containing thymol as an herbal drug for effective wound healing, J. Appl. Polym. Sci. 129 (2013) 756-766.

[129] I.M. Martins, S.N. Rodrigues, M.F. Barreiro, A.E. Rodrigues, Release studies of thymol and p-cymene from polylactide microcapsules, Ind. Eng. Chem. Res. 51 (2012) 11565-11571. 


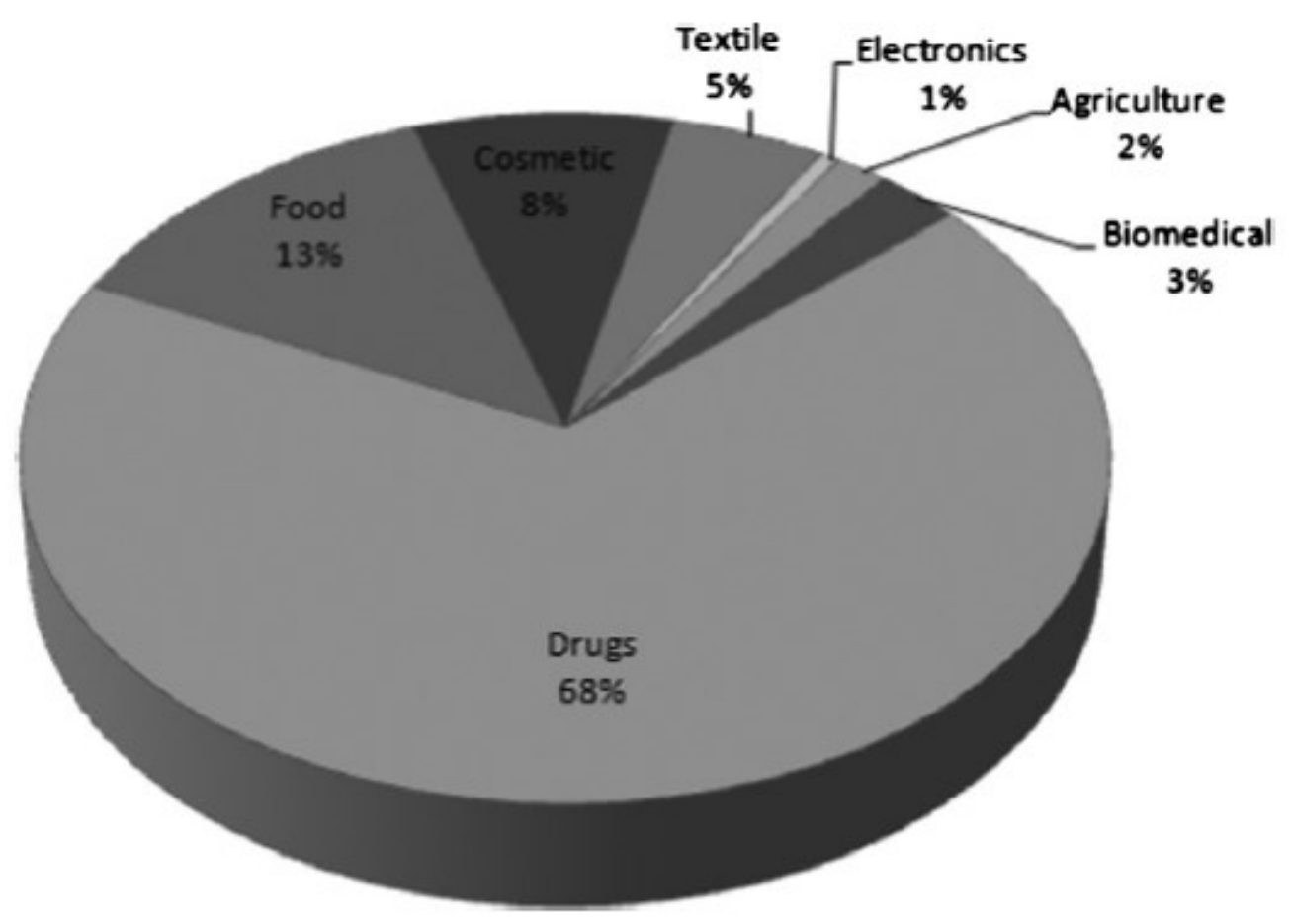

Fig. 1. Schematic representation of the statistical distribution of microencapsulation over different fields of application (obtained on ISI web of knowledge, April 2013; timespan = all years and keywords: microcapsules and application) [7]. 


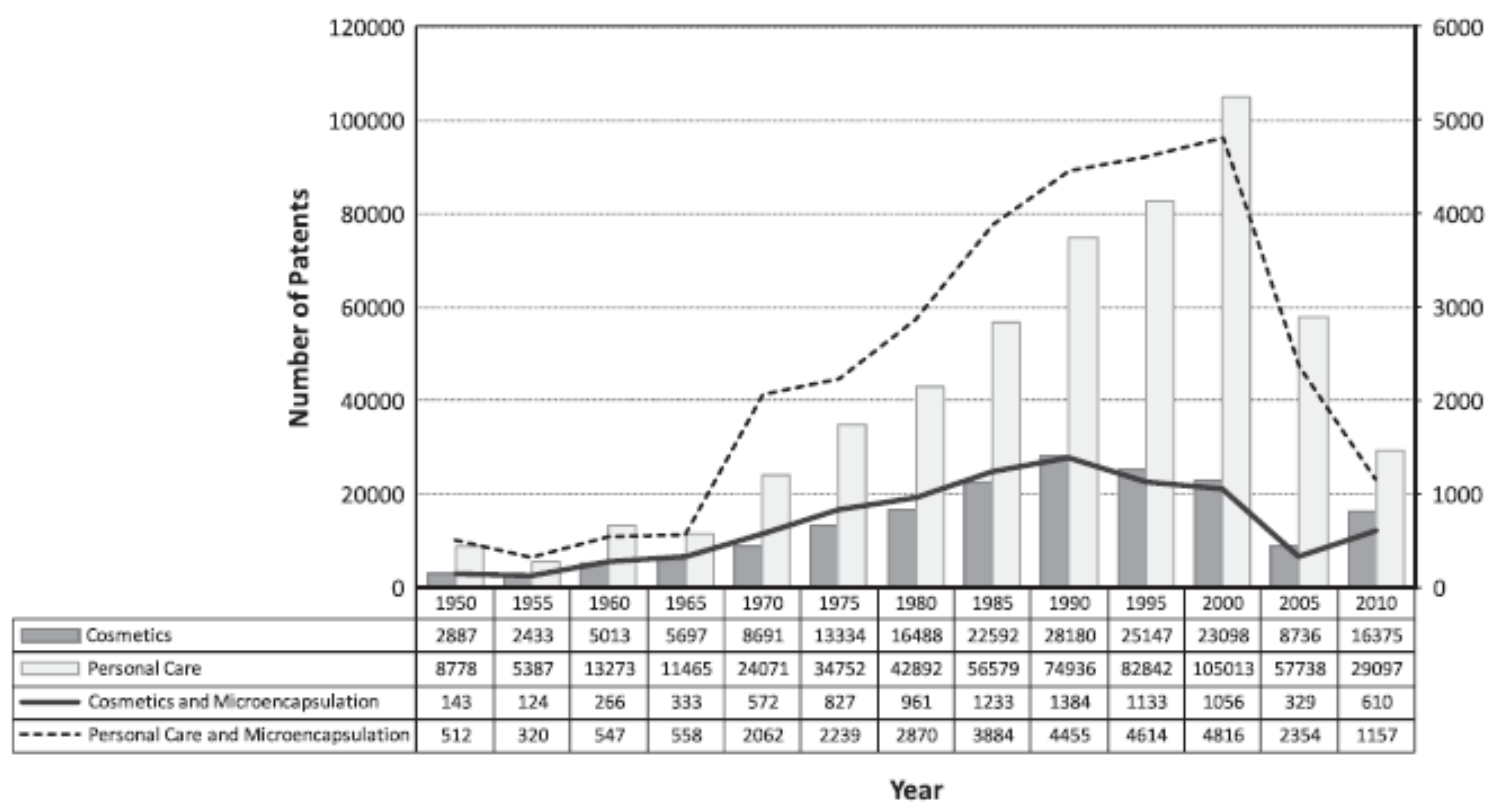

Fig. 2. Number of patents published in the period from 1950 to 2010 (obtained on free patents online database, September 2013; Keywords: cosmetics, personal care and microencapsulation).
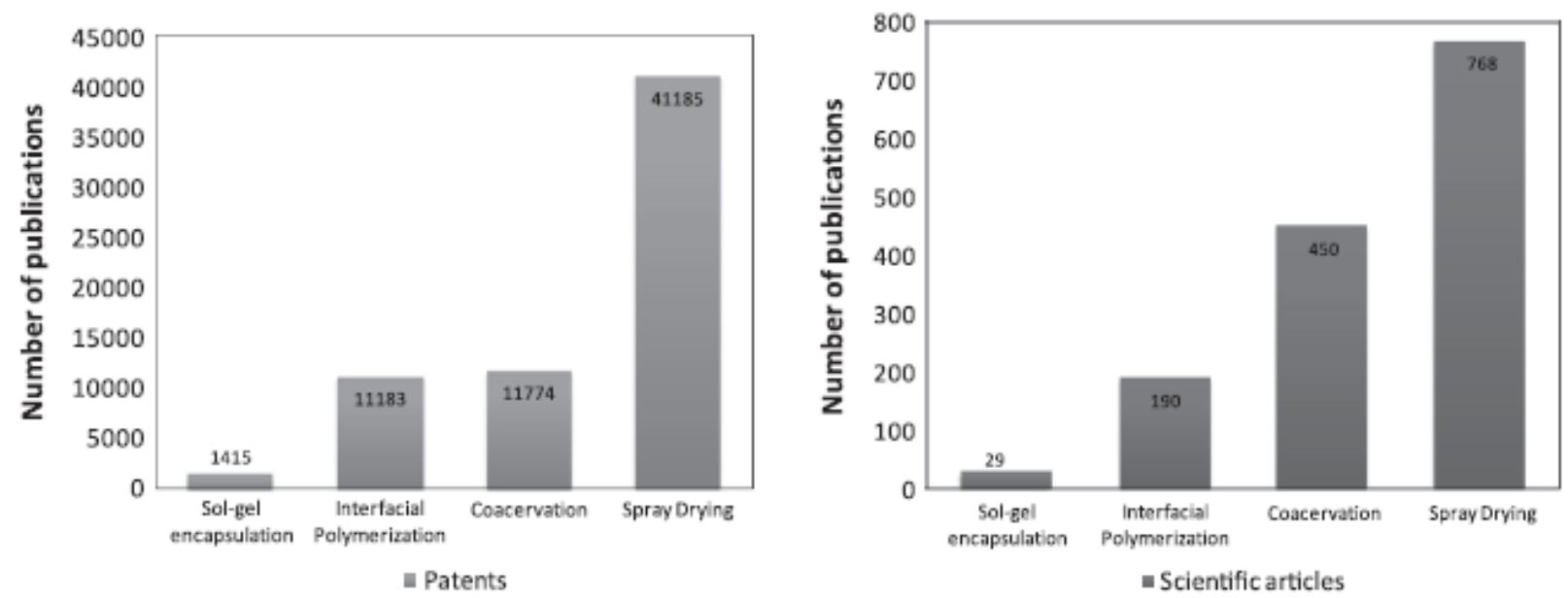

Fig. 3. Microencapsulation methods by publication type (obtained on: (a) free patents online database and (b) web of science, January 2014; Keywords: microencapsulation and sol-gel encapsulation or interfacial polymerization or coacervation or spray drying). 


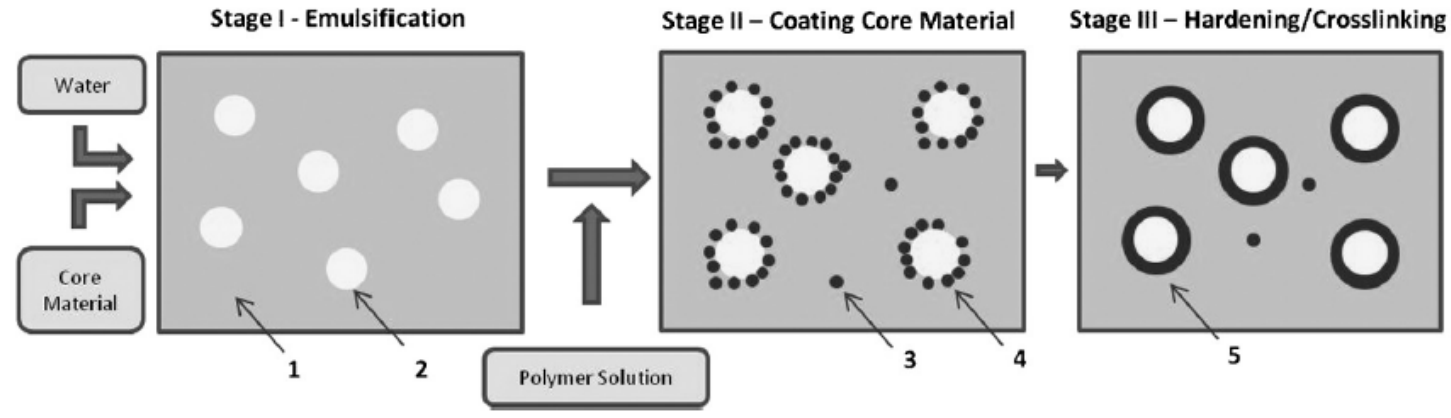

Fig. 4. General process scheme for microcapsule preparation by coacervation. (1) water; (2) core material; (3) polymer; (4) deposition the polymer coating upon core material; (5) microcapsules. Adapted from Martins et al. [37].

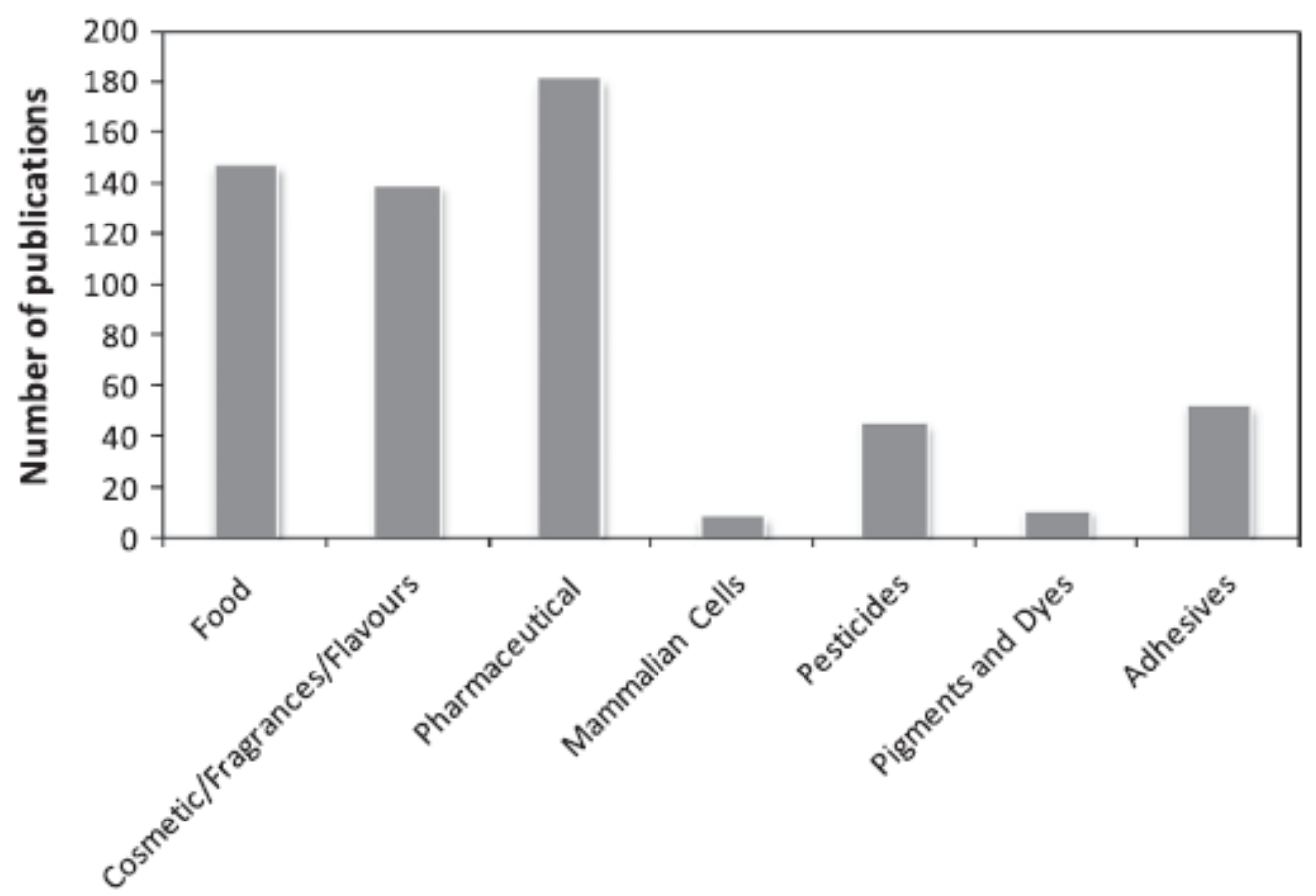

Fig. 5. Number of publications for all years (obtained on data base 2013 web of science, April 2013; keywords: coacervation and application). 


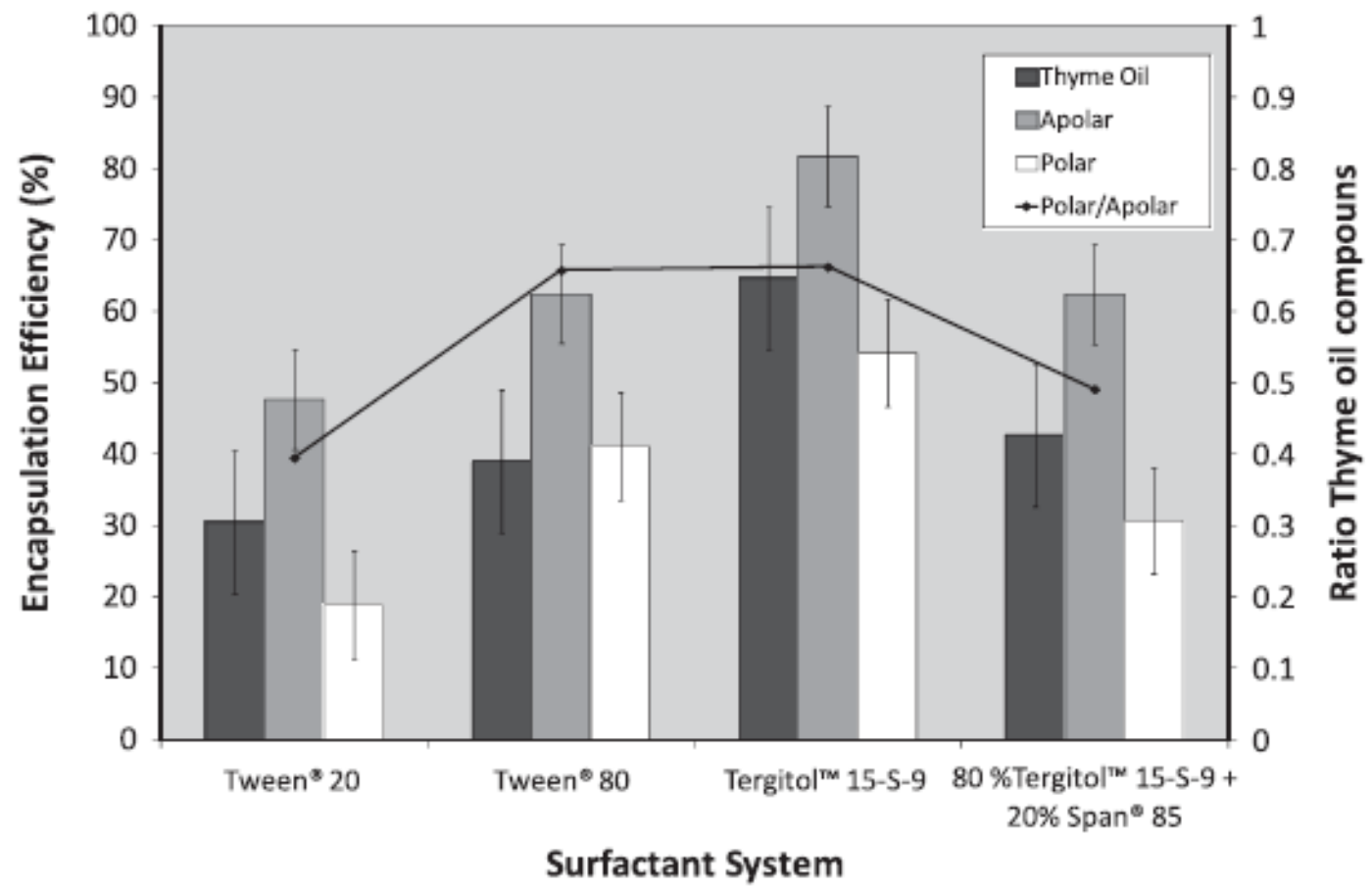

Fig. 6. Values of encapsulation efficiency for thyme oil and their apolar and polar compounds and encapsulation efficiency ratio apolar/polar for all surfactant system. Adapted from Martins et al. [56].

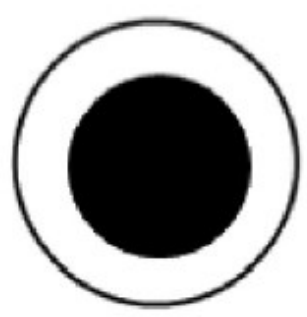

(a)

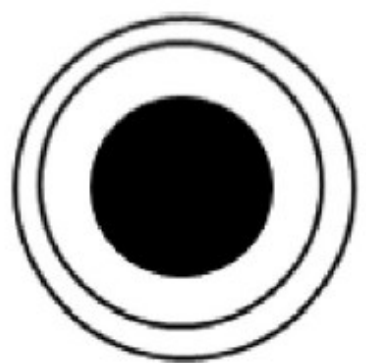

(b)

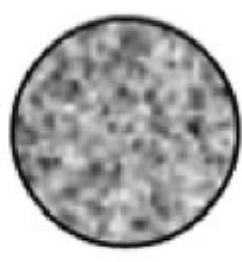

(c)

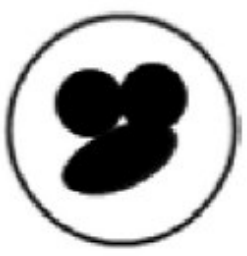

(d)

Fig. 7. Different morphologies of microcapsules: (a) reservoir type, (b) double shell, (c) matrix, (d) polynucleated [105] 


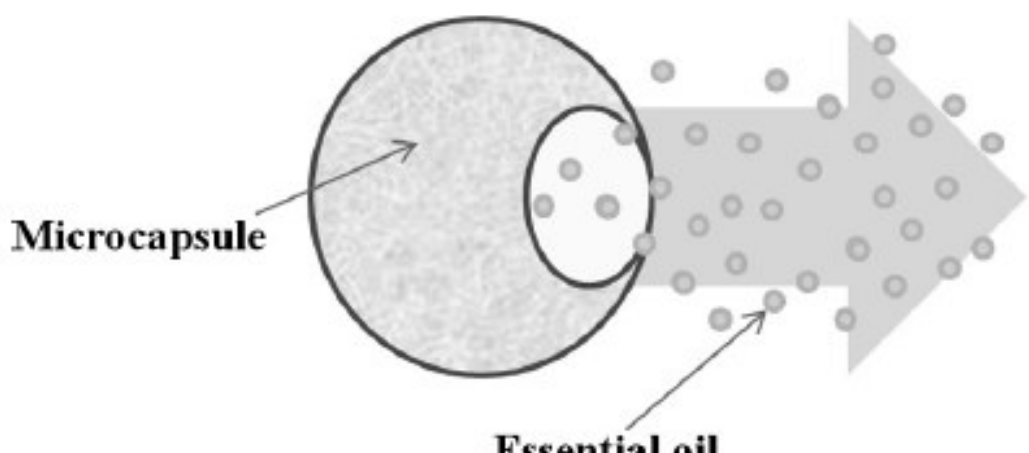

Fig. 8. Schematic representation of oil release through the polymeric microcapsule shell

Microcapsules Morphology

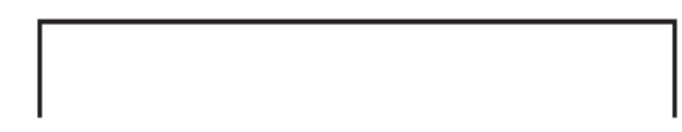

Matrix systems

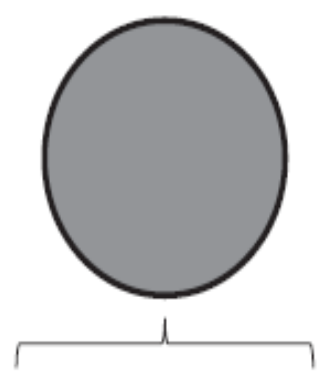

Matrix dispersions

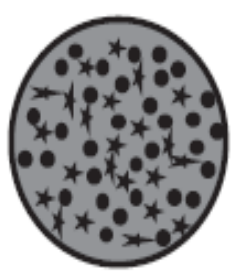

Geometry dependent release
Matrix solutions

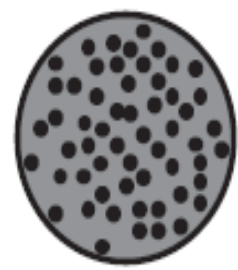

Zero order release
Reservoir systems

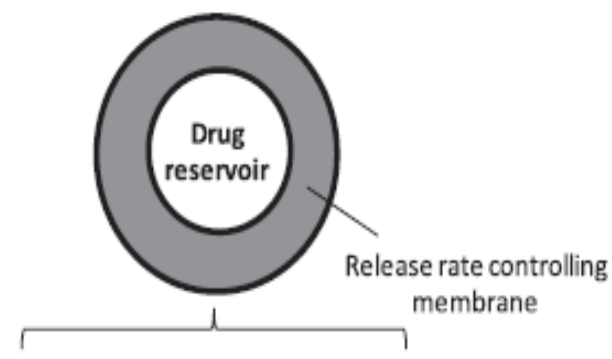

Constant activity source

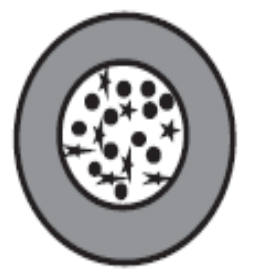

Non-constant activity source

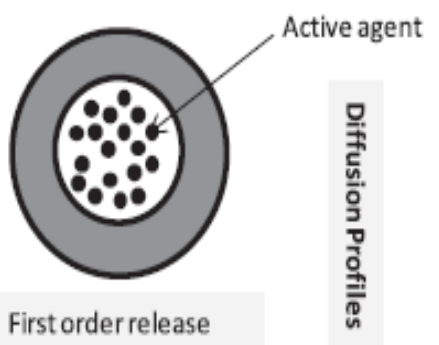

- individual drug molecules

* drug crystals and/or amorphous aggregates

Fig. 9. Classification scheme for diffusion controlled drug delivery systems. Adapted from Siepmann and Siepmann [126] 


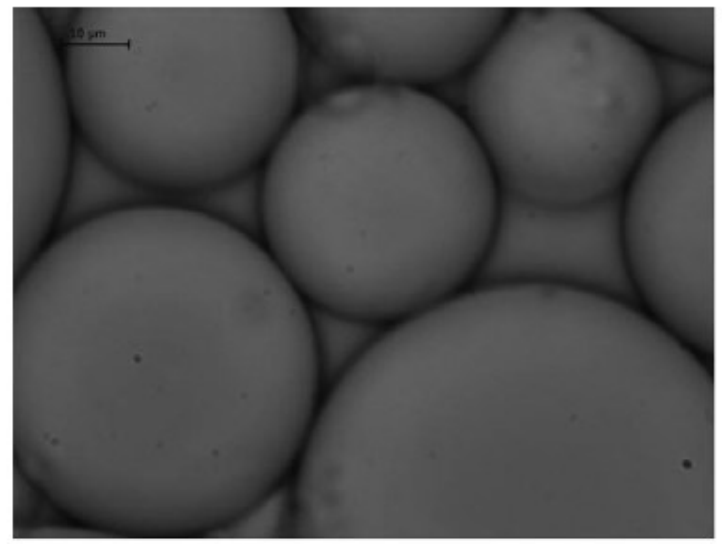

(a)

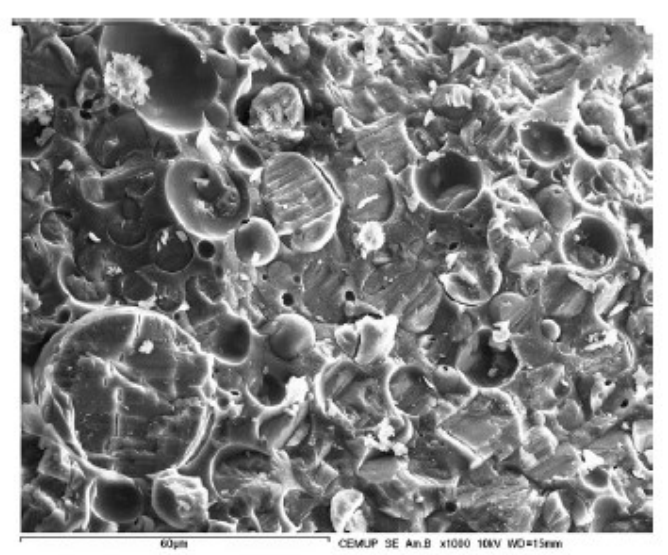

(b)

Fig. 10. Optical (a) and Cryo-SEM (b) microscopy images of PLA microcapsules with thyme oil. Magnification of images: 1000x.

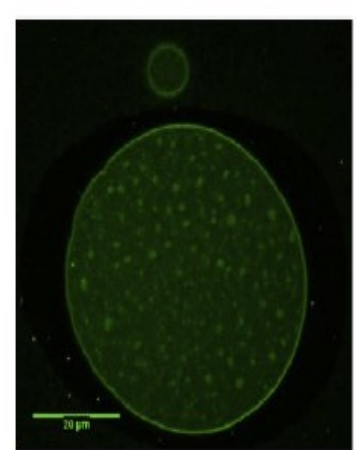

(a)

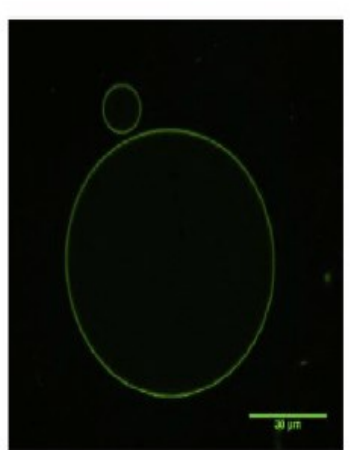

(b)

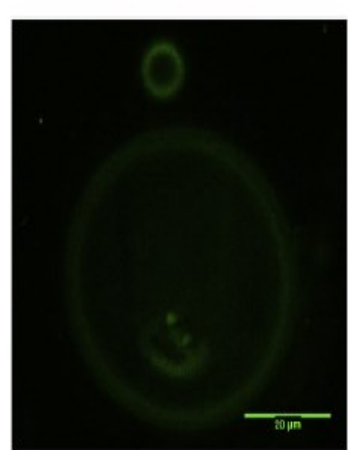

(c)

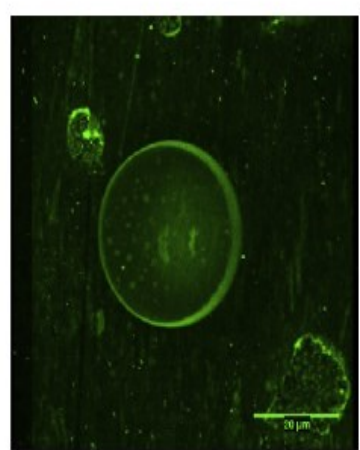

(d)

Fig. 11. Fluorescence confocal microscopy images of the PLA microcapsules with thyme oil (PLA labeled with Coumarin 6) (a) upper plane being the initialization level (b) middle plane (movie with pictures at different $z$, supplementary information) (c) lower plane (d) visualization of the 3D shape (movie, supplementary information). 

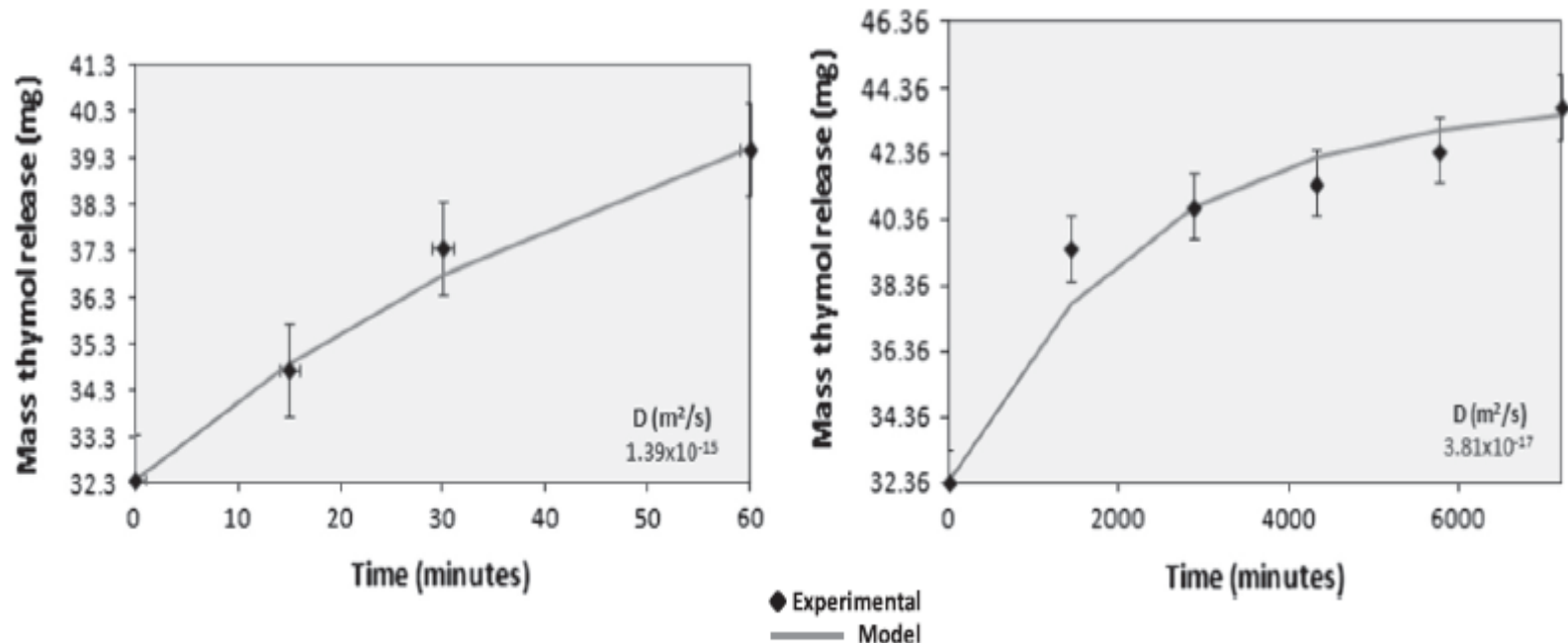

Fig. 12. Comparison between experimental and model results for thymol released from PLA microcapsules solution in first hour and for 5 days. Adapted from Martins et al. [96]. 
Table 1

Patent processes for microencapsulation by coacervation.

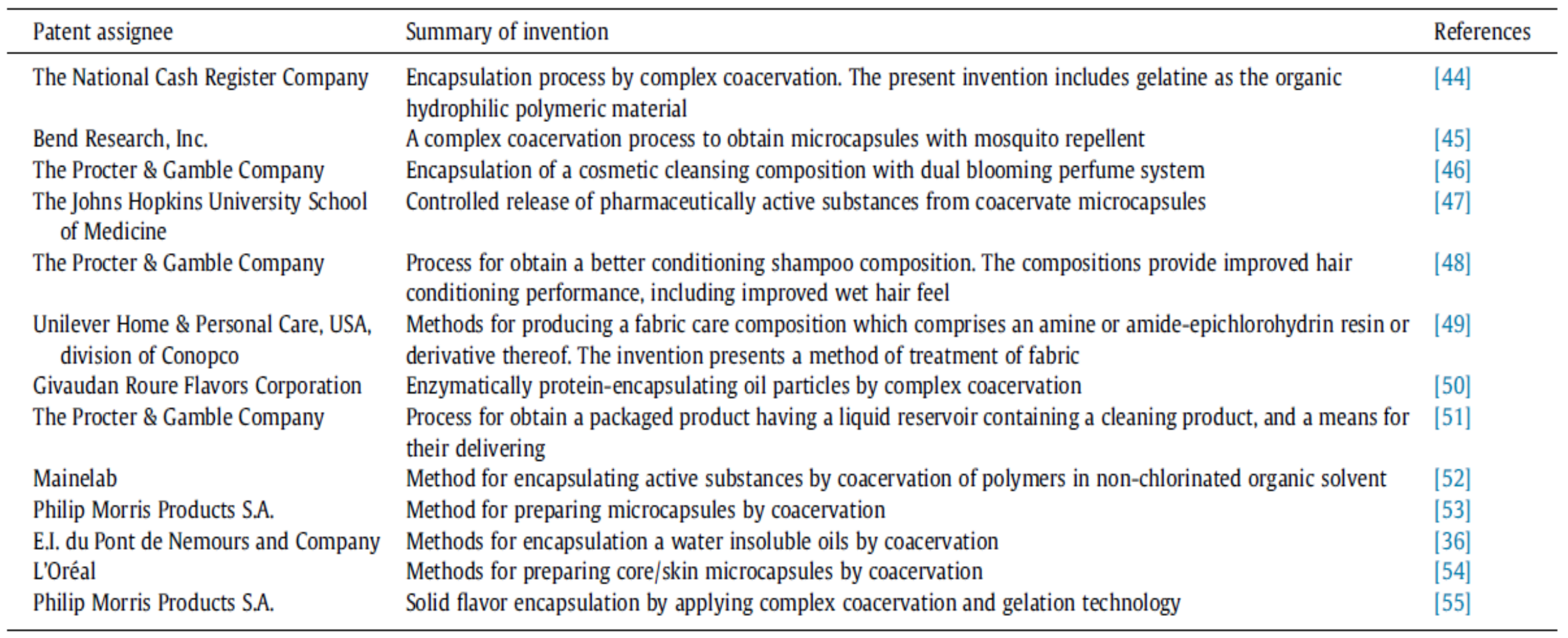


Table 2

Examples of shell materials used in coacervation systems. Adapted from Boh and Sumiga [57].

\begin{tabular}{|c|c|c|c|}
\hline & Shell material & & References \\
\hline \multirow[t]{5}{*}{ Simple coacervation } & Soy glycinin & & [58] \\
\hline & Gelatin & & [59] \\
\hline & Casein & & [60] \\
\hline & Chitosan & & [61] \\
\hline & Polyvinyl alcohol & & [62] \\
\hline \multirow[t]{6}{*}{ Complex coacervation } & Shell material: 1st polymer & Shell material: 2nd polymer & \\
\hline & Gelatin & Gum arabic & [63] \\
\hline & Albumin & Carboxymethyl cellulose & [64] \\
\hline & Collagen & Polyacrylates & [65] \\
\hline & Gelatin & Polyphosphates & [66] \\
\hline & Gelatin & Polysilicate & [67] \\
\hline
\end{tabular}

Table 3

Representative list of encapsulated essential oils.

\begin{tabular}{lll}
\hline Essential oil & Application & References \\
\hline Lemon & Cosmetic & {$[81,82]$} \\
Thyme & Cosmetic & {$[37,83]$} \\
Citronella & Pharmaceutical and insect repellent & {$[84,85]$} \\
Vanilina & Cosmetic & {$[86]$} \\
Menthol & Food and pharmaceutical & {$[87,88]$} \\
Eucaliptol & Insect repellent & {$[89]$} \\
Clove & Textile & {$[90]$} \\
Peppermint & Food and pharmaceutical & {$[91,92]$} \\
\hline
\end{tabular}


Table 4

Survey of essential oils encapsulated by coacervation and their major applications. Adapted from Magdassi et al. [40].

\begin{tabular}{lll}
\hline Core material & Method & Application \\
\hline Mint, orange or eucalyptus oils & Complex coacervation & Cosmetics and food \\
Orange oil & Heat denaturation & Food and pharmaceuticals \\
Thyme oil & Coacervation & Cosmetics \\
Rosemary oil & Simple coacervation & Food and pharmaceuticals \\
Rose perfume oil & Complex coacervation & Cosmetics \\
Lemon oil & Complex coacervation & Cosmetics \\
Citronella oil & Simple coacervation & Insect repellents \\
Peppermint oil & Complex coacervation & Pharmaceuticals \\
Cinnamon oil & Simple coacervation & Food \\
\hline
\end{tabular}

Table 5

Representative list of release models of active agents through the polymeric membranes of microcapsules.

\begin{tabular}{lll}
\hline Active agent & Release model & References \\
\hline Perfume & Zero order model for films geometry & {$[106]$} \\
Drug & Fick's second law model for spherical geometry & {$[112]$} \\
Drug & Single pellet model & {$[123]$} \\
& Multiple-pellet model & \\
Drug & Single pellet model (solid drug coated with a semi-permeable membrane) & {$[116]$} \\
Dye (oils) & Single shell model & {$[124]$} \\
Propolis & Fick's second law model for films geometry & {$[125]$} \\
\hline
\end{tabular}

